\title{
The Effect of Educating Self-Care Behaviors to Patients With Heart Failure in Hospitals of Zahedan
}

\author{
Maryam Seraji ${ }^{1,{ }^{*}}$, Peyman Tabatabaie ${ }^{1}$, Fatemeh Rakhshani ${ }^{2}$, Mahnaz Shahrakipour ${ }^{1}$ \\ ${ }^{1}$ Zahedan University of Medical Sciences, Zahedan, IR Iran \\ 2 Health Promotion Research Center, Zahedan University of Medical Sciences, Zahedan, IR Iran \\ *Corresponding author: Maryam Seraji, Department of Health Education, Zahedan University of Medical Sciences, Zahedan, IR Iran. Tel.: +98-9155432685, Fax: +98-5413220501, E-mail: \\ serajimaryam@gmail.com.
}

Received: April 06, 2013; Revised: May 08, 2013; Accepted: May 20, 2013

Background: Heart failure is a chronic disease in the elderly. Self-care education has a significant role in preventing the disease, its progress, and complications.

Objectives: The present study aimed to assess the effect of training on self-care behaviors among patients with heart failure in hospitals of Zahedan City in 2012.

Materials and Methods: The present study had a quasi-experimental interventional design with control group, and was conducted in CCU and post-CCU wards in hospitals affiliated to Zahedan University of Medical Sciences in 2012. There were 140 hospitalized patients in two equal groups of case (70 people) and control (70 people). The case group received an educational package including a pamphlet, an educational CD, and educational footage for their cell phone. After one month, they took the posttest. The data were analyzed by SPSS statistical software ver. 18 .

Results: After training, the mean scores of awareness, attitude and practice among patients in the case group were respectively $8.93 \pm$ $2.32,47.69 \pm 2.21$, and $66.04 \pm 3.44(\mathrm{P}<0.0001)$. The mean score difference of attitude in the intervention group was 17.78 \pm 7.0 , and $3.30 \pm$ 6.85 in the control. The mean score difference of practice in the intervention group was $26.57 \pm 6.37$, and $2.08 \pm 7.16$ in the control group $(\mathrm{P}$ $<0.0001)$.

Conclusion: The results of the present study showed that self-care behaviors in patients with heart failure were influenced by awareness, and their practice improved with increasing their knowledge. Therefore, it is recommended to give an educational pamphlet video to patients with heart failure.

Keywords: Health; Self Care; Heart Failure; Hospitalization

\section{Background}

Cardiovascular diseases are among the most prevalent causes of mortality in most countries, and the most important cause of disability [1]. At the beginning of the 21st century, cardiovascular diseases were responsible for almost half of the mortality in developed countries, and 25 percent of deaths in developing countries. They would be the most important cause of death in developing countries by 2020 (one in every 3 deaths) [1]. These diseases are known as the first cause of death in Iran, and impose huge healthcare, social and economic burden on the society. According to the statistics released by Deputy for Health in Ministry of Health, there were 369 cases of death caused by cardiovascular diseases each day in 2003 [2]. Most of the cardiovascular diseases would finally change to a disease called congestive heart failure (CHF) after treatment [3]. CHF is a pathophysiologic condition in which the heart output cannot supply the need of body tissues to oxygen and nutrients [4]. In fact, HF is a complex clinical syndrome with different causes, in which a functional defect in heart leads to disorder and failure of heart in emptying or filling with normal ventricular end-diastolic pressure. Therefore, patient cannot do his or her activities without symptoms like dyspnea, fatigue or fainting [5]. The final phase of the chronic cardiovascular diseases is heart failure [6]. The increasing prevalence and incidence of the disease in different societies, the increase in frequency of ischemic heart diseases, high mortality, short life of the patients with CHF, frequent hospitalizations plus high costs are important aspects of HF [7]. Studies show that at least $50 \%$ of patients with HF do not adhere to their therapeutic recommendations, which leads to their rehospitalization and complications of HF [8]. The incidence of the disease increases with age, and its prevalence increases in com-

Implication for health policy/practice/research/medical education:

with applying the self-care behaviors, it can improve the life style of heart failure patients. In the future studies, researchers and health care planners can use the results of this study, This Study also leads to making the training production of booklat and video package that is useful for all heart failure patients (particularly Illiterate patients).

Copyright ( 2013, Health Promotion Research Center. This is an Open Access article distributed under the terms of the Creative Commons Attribution License(http:| creativecommons.org/licenses/by/3.0), which permits unrestricted use, distribution, and reproduction in any medium, provided the original work is properly cited. 
munities with increasing number of elderly. According to the American Heart Association in 2009, about 2\% of the population had heart failure [9]. One of the best ways to prevent the incidence, progress, and complications of the disease is to train self-care to patients [10]. Self-care is one of the most important aspects of treatment in patients with heart failure [2]. Heart failure is one of the most common causes of rehospitalization within 60 days after discharge [11]. Most of the studies state that about $50 \%$ of the people are hospitalized because of heart failure after retreatment [9]. Heart failure is among the most expensive causes of hospitalization [2]. It also causes 12 to 15 million visits in private offices, and 6.5 million days of hospitalization each year (74). The cost of rehospitalization in Iran was $\$ 4$ million in 2003 [11]. Frequent hospitalizations reduce the quality of life. In a study, 39 percent of the participants were rehospitalized 14 days after discharge due to their deteriorating conditions. The most important recurrence signs and revisits were dyspnea and edema due to daily activities. 59\% of rehospitalizations were due to sodium consumption and water retention in body [9]. Self-care in heart failure is really important because most of the care in these patients occurs away from the healthcare team [12]. Adherence to self-care behaviors in patients with chronic diseases is especially important, and patients can affect their comfort, functioning and disease process by gaining self-care skills [13]. Most of the reasons for lack of adherence to treatment and aggravation of HF can be prevented by educational interventions. Learning how to manage chronic conditions is the backbone of self-care [14]. Studies show that strategies focusing on educational needs determined by patients are more successful than those determined by others [15]. Increasing awareness of patients through training selfcare by itself reduces readmissions to hospitals especially to CCU [16]. One of the major factors that improve the quality of treatment is patients' participation in treatment and self-care. Lack of patient's awareness of self-care especially about adhering to therapeutic regimens is followed by negative consequences for patient's health and frequent hospitalizations [17]. Poor self-care behaviors and lack of adherence to diet and therapeutic regimen increase rehospitalization of patients with HF by 20-60 percent [17]. Self-care is one of the most important aspects of treatment [2], and is the pillar of managing HF, which includes adhering to low salt diet, medical regimen and so on to maintain body's physiologic stability and health [18]. A sudden weight gain, daily weighing, adhering to food and drug regimen, regular physical activity, abstinence from smoking, contacting the physician in case of edema on foot, ankle, shin, or stomach, measuring daily amount of urine, and not drinking a lot of liquids are examples of self-care behaviors [2].

\section{Objectives}

Making people aware of the disease and its risk factors is the pillar of education. Giving information, changing attitudes, and changing behaviors are the main objectives which control the disease and improve preventive behaviors [1].

\section{Materials and Methods}

This quasi-experimental study with control group was conducted on 140 patients with HF admitted to CCU and cardiovascular disease wards of Khatamolanbia and Aliebn-e Abitaleb hospitals in Zahedan. The patients were divided into intervention group (70 people) and control group (70 people). The self-care score difference before and after training was measured by using the following formula, the confidence interval of $95 \%$, and test power of $80 \%$.

$$
\mathrm{n}=(\mathrm{Z} 1-\alpha / 2+\mathrm{Z} 1-\beta)^{2}\left(\mathrm{~S}^{2}+\mathrm{S} 2^{2}\right) / \leftarrow(\dot{\mathrm{x}} 1-\dot{\mathrm{x}} 2)^{2}
$$

The sample size for each group was calculated as 53 , but to cover up for the possible dropouts of $15 \%$ (17 people), 70 people were recruited for each group. Sampling was performed in nonprobability method (convenience) in the way that researchers went to the hospitals and interviewed patients with HF. Patients who were interviewed on a day were excluded on next days. To avoid bias (the effect of different treatments in two hospitals), the intervention and control groups were selected from both hospitals. Therefore, 35 people were selected for intervention, and 35 people were selected for control from Khatamolanbia Hospital. The same was performed for Aliebn-e Abitaleb Hospital. While in one hospital a sample for the intervention was being selected, a sample for the control group was being selected in the other hospital. After assessing patients for exclusion criteria, and in case they were willing to enter the study, the questionnaire was filled out by the questioner. Preferably on the final days of hospitalization (when the patient was medically improving and ready for training), the information about the objectives of the study and its length was given to the patients face to face. Both the case and the control groups received the conventional training by nurses. The case and control groups were matched for age, sex, and education. There were two training sessions: the first one included a lecture of 45 minutes about the content of the pamphlet, showing the footage simultaneously, and issuing the educational CD to the patients with emphasis on increasing the awareness, attitude and practice of self-care behaviors. The second session was held the next day in a $\mathrm{Q}$ and A manner about the training material. Finally, the researcher concluded the session by correcting wrong information and attitudes. After a month of waiting, the researcher went to the patients' home one by one, and performed the posttest. In this study, data were collected through a questionnaire which was filled by 
the researcher. The questions were in two sections: demographic information about patients with HF ( 9 items), and questions of awareness about self-care behaviors (13 items). Correct answer scored 3, 'I do not know' scored 2 and wrong answer scored 1. [If a person chooses 'I do not know', he or she is prepared to learn, but when a person chooses the wrong answer, first we have to correct his or her wrong information, and then teach him or her the right information.] Total scores ranged from 13 to 39. Questions on attitude toward self-care included 12 questions of 5 point Likert style (Totally agree, agree, no idea, disagree, totally disagree), and were scored from 1 to 5 (range 12-60). Questions on practice of self-care behavior included 16 5-option items (always, often, sometimes, rarely, never), and scored 1-5 (range 16-80). Content validity and face validity of the questionnaire were confirmed by an expert panel (including 7 cardiologists and 3 healthcare education experts), and received content validity ratio of $71 \%$, and content validity index of $81 \%$. Thirty patients with HF in the CCU were studied to determine its internal correlation. Cronbach's alpha was determined as $81 \%, 87 \%$, and $81 \%$ for awareness, attitude and self-care behaviors, respectively. The data were analyzed using descriptive statistical test, independent t-test, paired t test, Chisquare and correlation coefficient in SPSS ver 18.

\section{Results}

In this study, 140 patients with HF in two groups of intervention and control (70 patients each) were studied. Their mean age was $60.79 \pm 12.17$ years. As seen in Table 1 , most of the people were over 60 years old, were men (68.6\%), married (75.7\%), and illiterate (47.1\%). There were no significant differences between the case and control groups in any of the demographic and underlying variables(Table1). The most common complaint of the patients after HF was hypertension (74.9\%), followed by diabetes (52.9\%), myocardial infarction (67.1\%), pulmonary diseases (43.3\%), and gastrointestinal disorders (34.3\%). Most patients (54.3\%) had a history of two admissions to hospital.

\begin{tabular}{|c|c|c|c|}
\hline Variable & $\begin{array}{l}\text { Intervention Number } \\
\text { (percent) }\end{array}$ & Control Number (percent) & Pvalue \\
\hline Sex & & & $\mathrm{P}=0.27$ \\
\hline Male & $42(60)$ & $48(68.6)$ & \\
\hline Female & $28(40)$ & $22(31.4)$ & \\
\hline Marital status & & & $\mathrm{P}=0.58$ \\
\hline Married & $51(72.9)$ & $53(75.7)$ & \\
\hline Widowed & $19(27.1)$ & $14(20.0)$ & \\
\hline Divorced & $0(0)$ & $3(4.3)$ & \\
\hline Job & & & $\mathrm{P}=0.35$ \\
\hline Housekeeper & $29(41.4)$ & $31(44.3)$ & \\
\hline Worker-farmer & $18(25.7)$ & $12(17.1)$ & \\
\hline Clerk-retired & $16(22.9)$ & $11(15.7)$ & \\
\hline Self-employed & $7(10.0)$ & $16(22.9)$ & \\
\hline Education & & & $\mathrm{P}=0.7$ \\
\hline Illiterate & $47(67.1)$ & $47(67.1)$ & \\
\hline Elementary-middle & $14(20.0)$ & $15(21.4)$ & \\
\hline $\begin{array}{l}\text { High school diploma and } \\
\text { higher }\end{array}$ & $9(12.9)$ & $8(11.4)$ & \\
\hline Underlying diseases & & & $\mathrm{P}=0.38$ \\
\hline Hypertension & $52(74.9)$ & $52(74.9)$ & \\
\hline Diabetes & $37(52.9)$ & $27(38.6)$ & \\
\hline Myocardial infarction & $34(48.6)$ & $47(67.1)$ & \\
\hline Pulmonary diseases & $24(34.3)$ & $17(24.3)$ & \\
\hline Gastrointestinal diseases & $14(20.0)$ & $24(34.3)$ & \\
\hline Previous hospitalization & & & $\mathrm{P}=0.24$ \\
\hline No history & $3(4.3)$ & $1(1.4)$ & \\
\hline Once & $9(12.9)$ & $16(22.9)$ & \\
\hline Twice & $20(28.6)$ & $14(20.0)$ & \\
\hline More than twice & $38(54.3)$ & $39(55.7)$ & \\
\hline
\end{tabular}


The paired t test showed that mean scores of awareness, attitude and practice regarding self-care behaviors in patients with HF before training and after training were significantly different in the intervention group $(\mathrm{P}<0.0001)$.
Likewise, the mean scores of awareness, attitude and practice regarding self-care behaviors in patients with HF in the control group before and after intervention were significantly different $(\mathrm{P}<0.0001)$.

Table 2. Comparing the Mean and Standard Deviation of Scores of Awareness, Attitude and Practice Regarding Self-Care in Patients with HF Before and After Training in Intervention and Control Groups

\begin{tabular}{llll}
\hline Group & Awareness of 39 & Attitude of 60 & Practice of 80 \\
\hline Intervention, Mean \pm SD & & & \\
$\quad$ Before & $8.23 \pm 3.79$ & $29.90 \pm 6.35$ & $39.40 \pm 5.49$ \\
After & $21.93 \pm 2.32$ & $47.69 \pm 2.89$ & $66.04 \pm 3.44$ \\
Changes & $13.78 \pm 4.27$ & $17.78 \pm 7.0$ & $26.57 \pm 6.37$ \\
\hline P value & $\mathrm{P}<0.0001$ & $\mathrm{P}<0.0001$ & $\mathrm{P}<0.0001$ \\
Control, Mean \pm SD & & & \\
Before & $8.07 \pm 3.27$ & $32.35 \pm 6.10$ & $43.17 \pm 6.59$ \\
After & $10.10 \pm 2.03$ & $35.76 \pm 2.95$ & $45.33 \pm 3.64$ \\
\hline Changes & $2.11 \pm 3.58$ & $3.30 \pm 6.85$ & $2.08 \pm 7.16$ \\
P value & $\mathrm{P}<0.0001$ & $\mathrm{P}<0.0001$ & $\mathrm{P}<0.0001$ \\
\hline
\end{tabular}

Furthermore, there was a significant association between scores of practice-awareness, practice-attitude and awareness-attitude after training $(\mathrm{P}<0.0001)$, and the intensity of correlation between awareness and practice was the highest.

\section{Discussion}

Self-care behaviors in patients with heart failure are important, and intervention efforts aimed at improving the treatment of patients is essential. The results of this study indicate that Dadd self-care behaviors in heart failure patients with an increased awareness of patients improved their performance. In the present study, the mean age of patients in the intervention group was 60.97 \pm 12.17 years, and was $60.77 \pm 12.26$ years in the control group. The mean age in Sneed (19) study was 60.6 years like ours, and was $66.3 \pm 1$ in Parvin Mangulian Shahrbabaki study (20), which are in line with our study. Meanwhile, the mean age in Van Der Wal study (21) was $72 \pm 11$. The prevalence and incidence of HF increase with age, such that in the United States, nearly $1 \%$ of people over 50 , and $10 \%$ of people over 80 have HF (6). Forty-two people (60\%) in the intervention group and 48 people (68.6\%) in the control group were men. In studies by Gregg [19], Sneed [20], and Van de Wal [21], men comprised 71\%, 62.4\%, and $60 \%$ of the patients, respectively. In Abbas Heidari's study, men comprised $67 \%$ of the patients, which is in line with our study [6]. Most patients in the intervention and the control group were illiterate. (Both groups 47.1) In Figer's [22] study, most patients had low education. In Abbas Heidari's study, 39.5\% of patients were illiterate. Also 50.5\% in Zahra Rahnavard's study [23], which agrees with our study, and of course is related to participant's age.
Fifty-one people (72.9\%) in the intervention group and 53 people (75.7\%) in the control group were married. That figure was 73.9\%, 80.6\%, and 55\% in Zahra Rahnavard's, Abbas Heidari's and Mangulian Shahrbabaki's studies, respectively, which agrees with our study [23-25].

In the intervention group, 29 people (41.4\%) were housekeepers, and 18 people (25.7\%) were workers or farmers. In the control group, 31 people (44.3\%) were housekeepers and 16 people (22.9\%) were self-employed. In Rahnavard's study, 64.1\% were housekeepers [24], and in Shojafard's study $72.8 \%$ were housekeepers [2], which agrees with our study. Thirty-eight people (54.3\%) in the intervention group and 39 people (55.7\%) in the control group had a history of admission more than twice. Yousefi found that most patients (48\%) were hospitalized more than 3 times, and $81.5 \%$ had a history of rehospitalization [26]. Regarding the underlying diseases in patients with HF, the most common diseases were, in order, hypertension $74.9 \%$, diabetes $52.9 \%$, history of MI $48.6 \%$, and pulmonary diseases $34.3 \%$. Those in the control group were hypertension $74.9 \%$, MI $67.1 \%$, diabetes $38.6 \%$, and gastrointestinal diseases 34.3\%. In Shiao-PIwang et al.'s study, the most important symptoms in hospitalized patients were, in order, fatigue, respiratory distress, edema, low appetite, palpitation, and dizziness [27]. Alison Gay studied 125 patients with HF and found the most common underlying diseases as hypertension $69 \%$, diabetes $54.4 \%$, and cardiovascular diseases $49.6 \%$ [28]. Novin Nek Hovin found the same for a Vietnamese population as hypertension $19.8 \%$, diabetes 13.5\%, and COPD 4\% [29]. Rahnavard reported hypertension $61.4 \%$, hyperlipidemia $47.8 \%$, and other diseases except HF $37.8 \%$ (65), which are all in accordance with our findings. Ischemic heart disease (IHD) can uncover HF by aggravating ventricular function [30]. Further- 
more, hypertension can also transit heart from compensation phase to heart failure [1]. As seen in these studies, patients with HF in both groups had the underlying diseases of hypertension and MI, which confirms the role of underlying diseases as risk factors for HF.

This study showed that training patients with HF increases awareness, attitude and practice regarding selfcare behaviors, and improves self-care practice and behaviors. Sethares reported the effect of interventions in changing health beliefs of patients with HF [31]. Holland confirmed the efficacy of interventions on reducing readmission of patients with HF and on reducing their mortality in his review study of 30 interventional studies [32]. Krumholz et al. studied the efficacy of an educational intervention in preventing readmission in patients with $\mathrm{HF}$, and showed a significant reduction in adverse clinical outcomes and costs due to HF [30]. In our study, the scores of awareness, attitude and practice increased significantly in the intervention group compared to before intervention, and with the control group, which shows the significant effect of training for these patients. The mean difference in the intervention group showed a higher change compared to the control group, which is due to the educational package. The mean scores in the control group had significantly increased at the end of the study compared to before intervention, but the increase was much less than that in the intervention group. It seems that this increase is due to the routine training that nurses give patients and their readmissions. Hanyu states that training patients is the key to treat HF. Hanyu found that people who had the highest knowledge were those who had a history of admission, and those who had a longer history of HF [33]. Delavar found a meaningful association between awareness and the number of admissions due to heart diseases, that is, $27.1 \%$ of those with a history of admission had good knowledge, and $59.4 \%$ had average knowledge. Only $2.6 \%$ of people without a history of admission had good knowledge $(\mathrm{P}<0.0001)$. In addition, the association between awareness and training by physician and nurse was significant $(\mathrm{P}<0.0001)$, in that $42.2 \%$ of those trained by nurses had good knowledge, $57.6 \%$ had average knowledge, and only $10.1 \%$ of the untrained people had good knowledge [34]. Dalton et al. showed that patients' participation in educational courses for self-care held by nurses in hospitals increases their knowledge about adhering to diet and medical regimen, and patients were more sensitive to consuming food that was harmful for them [35]. They also showed that such patients adhered to therapeutic regimen better after discharge, and had lower costs and hospitalization and readmission [35]. Regarding the correlation between variables of this study, scores of practice-awareness, practice attitude, and awareness-attitude had a meaningful association, and the intensity of correlation between awareness and practice was more. Artinian [30] found a significant association between awareness and self-care behaviors, and so did we. This finding confirms the theory of Orem [36], based on which awareness is a power that can enable the person for self-care. This awareness must be specific to the disease, be organized and meet the needs of self-care. Awareness is necessary but not enough. Learning self-care behaviors can lead the person to maintain health and well-being, increase person's adjustment with the disease, increase self-care ability in the person, and reduce disability and treatment costs.

\section{Conclusions}

Self-care behaviors are important in patients with HF, and it is necessary to apply interventions to improve such behaviors. The results of this study showed that self-care behaviors in patients with HF improved with their increased knowledge. Since awareness is a determining factor in self-care behavior in patients with HF, training programs should be planned to increase knowledge of patients about disease etiology, the right manner of taking medication, and self-care behaviors. Based on the findings of this study, educational pamphlet can increase patients' awareness, so it is recommended for patients with HF. Since patients with HF had fairly little knowledge about their disease and self-care regarding their disease, it is evident that using healthcare experts in healthcare center or educational programs, making educational pamphlets and films at reasonable costs that can be accessed by patients and their families, especially those with low education, can help control HF, because the first step in any practice is gaining enough knowledge in that field.

\section{Acknowledgements}

This manuscript is part of the master thesis and The authors are grateful for the financial support of this project by the health research deputy of Zahedan University of Medical Sciences.

\section{Authors' Contribution}

None declared.

\section{Financial Disclosure}

None declared.

\section{Funding/Support}

None declared.

\section{References}

1. Arici M, Walls J. End-stage renal disease, atherosclerosis, and cardiovascular mortality: is C-reactive protein the missing link? Kidney international. 2001;59(2):407-414

2. Shojafard J, Nadrian H, Baghiani Moghadam M, Mazloomi Mah- 
moodabad S, Sanati H, Asgarshahi M. The effect of training selfcare behaviors, advantages and obstacles in patients with heart failure in Tehran. Paraclin Faculty J. 2009;2(4):43-55.

3. Scotto CJ. The lived experience of adherence for patients with heart failure. Journal of Cardiopulmonary Rehabilitation and Prevention. 2005;25(3):158-163.

4. Griffin BP. Manual of Cardiovascular Medicine. Wolters Kluwer Health; 2012 .

5. Fabre JW. "Immune" functions of parenchymal cells might contribute to their susceptibility to rejection. Transpl Int. 1988;1(3):165-7.

6. Jaarsma T, Halfens R, Tan F, Abu-Saad HH, Dracup K, Diederiks J. Self-care and quality of life in patients with advanced heart failure: the effect of a supportive educational intervention. Heart Lung. 2000;29(5):319-30.

7. Wiener C. Harrison's Principles of Internal Medicine, Self-Assessment and Board Review. McGraw-Hill Companies,Incorporated; 2008.

8. Wang SP, Lin LC, Lee CM, Wu SC. Effectiveness of a self-care program in improving symptom distress and quality of life in congestive heart failure patients: a preliminary study. J Nurs Res. 2011;19(4):257-66.

9. Lorig KR, Sobel DS, Stewart AL, Brown Jr BW, Bandura A, Ritter P, et al. Evidence suggesting that a chronic disease self-management program can improve health status while reducing hospitalization: a randomized trial. Medical care. 1999;37(1):5.

10. Dungan KM, Osei K, Nagaraja HN, Schuster DP, Binkley P. Relationship between glycemic control and readmission rates in patients hospitalized with congestive heart failure during implementation of hospital-wide initiatives. Endocr Pract. 2010;16(6):945-51.

11. Bodenheimer T, Wagner EH, Grumbach K. Improving primary care for patients with chronic illness. JAMA: the journal of the American Medical Association. 2002;288(15):1909-1914.

12. Cohen TJ, Klein J. Cardiac resynchronization therapy for treatment of chronic heart failure. J Invasive Cardiol. 2002;14(1):48-53.

13. Hou N, Chui MA, Eckert GJ, Oldridge NB, Murray MD, Bennett SJ. Relationship of age and sex to health-related quality of life in patients with heart failure. Am J Crit Care. 2004;13(2):153-61.

14. Siegel JD, Rhinehart E, Jackson M, Chiarello L. Management of multidrug-resistant organisms in health care settings, 2006. American journal of infection control. 2007;35(10):S165-S193.

15. Kennedy A, Rogers A, Bower P. Support for self care for patients with chronic disease. BMJ: British Medical Journal. 2007;335(7627):968.

16. Artinian NT, Magnan M, Sloan M, Lange MP. Self-care behaviors among patients with heart failure. Heart Lung. 2002;31(3):161-72.

17. Dickson VV, Buck H, Riegel B. A qualitative meta-analysis of heart failure self-care practices among individuals with multiple comorbid conditions.J Card Fail. 2011;17(5):413-9.

18. Anderson RE, Tokuda S, Williams WL, Spellman CW. Low dose irradiation permits immunization of $\mathrm{A} / \mathrm{J}$ mice with subimmunogenic numbers of SaI cells. Br J Cancer. 1986;54(3):505-9.

19. Tscheliessnigg KH, Petutschnigg B, Gras D, Prenner G, Muller H. Insync experience in transplant list patients. Int J Thoracic Cardio Surg. 2001;3.

20. Sneed NV, Paul SC. Readiness for behavioral changes in patients with heart failure. Am J Crit Care. 2003;12(5):444-53.

21. van der Wal MH, Jaarsma T, Moser DK, Veeger NJ, van Gilst WH, van Veldhuisen DJ. Compliance in heart failure patients: the importance of knowledge and beliefs. Eur Heart J.2006;27(4):434-40.

22. Figar S, Galarza C, Petrlik E, Hornstein L, Rodriguez Loria G, Waisman $\mathrm{G}$, et al. Effect of education on blood pressure control in elderly persons: a randomized controlled trial. Am J Hypertens. 2006;19(7):737-43.

23. Zahra R, Zolfaghari M, Kazemnejad A, Hatamipour K. The quality of life and factors affecting it in patients with heart failure. J Nurse Midwifery. 2006;12(1):77-86.

24. Heidari A, Vaghei S. The role of self-concept of adjustment model on adhering to food diet in patients with HF. Ofogh Danesh $J$. 2012;17(4).

25. Mangulian Shahrbabaki P, Farrokhzadeh J, Hassanabadi Z. The effect of training self-care on awareness and practice of patients with heart failure. Shahrekord J Nurs. 2012;31(3):918.

26. Bennett SJ, Oldridge NB, Eckert GJ, Embree JL, Browning S, Hou N, et al. Comparison of quality of life measures in heart failure. Nurs Res. 2003;52(4):207-16.

27. Rudy EB, Vaska PL, Daly BJ, Happ MB, Shiao P. Permuted block design for randomization in a nursing clinical trial. Nurs Res. 1993;42(5):287-9.

28. Symons J, Wang L, Guallar E, Howell E, Dominici F, Schwab M, et al. A case-crossover study of fine particulate matter air pollution and onset of congestive heart failure symptom exacerbation leading to hospitalization. American journal of epidemiology. 2006;164(5):421-433.

29. Huyen NN, Jullamate P, Kangchai W. Factors related to Self-care Behaviors among Older Adults with Heart Failure in Thai Nguyen General Hospital, Vietnam. 2011.

30. Holland R, Battersby J, Harvey I, Lenaghan E, Smith J, Hay L. Systematic review of multidisciplinary interventions in heart failure. Heart. 2005;91(7):899-906.

31. Krumholz HM, Amatruda J, Smith GL, Mattera JA, Roumanis SA, Radford MJ, et al. Randomized trial of an education and support intervention to preventreadmission of patients with heart failure. Journal of the American College of Cardiology. 2002;39(1):83-89.

32. Sethares KA, Elliott K. The effect of a tailored message intervention on heart failure readmission rates, quality of life, and benefit and barrier beliefs in persons with heart failure. Heart Lung. 2004;33(4):249-60.

33. Ni H, Nauman D, Burgess D, Wise K, Crispell K, Hershberger RE. Factors influencing knowledge of and adherence to self-care among patients with heart failure. Arch Intern Med. 1999;159(14):1613-9.

34. Delavar S, Ramezanian F, Tadayonfar M. Awareness of patients with heart failure hospitalized in Vasei Hospital in Sabzevar of aggravating factors of the disease. Res J Sabzevar Uni Med Sci. 2011;15(3).

35. Dalton KL. Predictors of Compliance with Diet and Exercise Six Months After Heart Transplantation. Loyola University of Chicago; 1993.

36. Artinian NT, Magnan M, Sloan M, Lange MP. Self - care behavior among patients with heart failure. Heart Lung:;31(3):161-72. 